\title{
Death from Acute Hyponatremia Following Uneventful Abdominal Hysterectomy: Lessons from a Case Report
}

\author{
George A Vilos*, Angelos G Vilos and Basim Abu Rafea \\ London Health Sciences Centre, Canada
}

*Corresponding author: George A Vilos, Professor, Obstetrics and Gynecology, London Health Sciences Centre, Canada.

Received Date: May 31, 2019

Published Date: June 10, 2019

\begin{abstract}
A 38-year-old woman underwent a routine/uneventful abdominal hysterectomy for abnormal uterine bleeding (AUB) and uterine fibroids. Approximately 24 hours later, she developed severe hyponatremia $(\mathrm{Na}=118 \mathrm{mEq} / \mathrm{L})$, brain edema and coma, and she died 3 days later. The mechanism of hyponatremia was, likely, due to excessive and/or inappropriate fluid infusion of 2/3:1/3 solution. The inability to regulate her fluids and electrolytes ( $\mathrm{Na}$ and $\mathrm{K}$ ), was, likely, related to addback estrogen therapy given for 3 months preoperatively in conjunction with a GnRH agonist to optimize the patient's hemoglobin and shrink the uterus/fibroids. It has been known that postmenopausal women and men can regulate excessive hyponatremic fluid absorption and electrolytes better than premenopausal women implicating an estrogen role. Estrogen has been found to inhibit the Na/K-ATPase pump in a variety of tissues/organs including the brain. This woman's pathology of the endometrium was reported as proliferative indicating that enough estrogen may have been available to inhibit her Na/K-ATPase pump resulting in inability to regulate her fluids and electrolytes leading to her death.
\end{abstract}

Keywords: Hysterectomy; Hyponatremia; Death; GnRH agonist; Addback therapy

\section{Introduction}

Hysterectomy is the most frequently performed gynecologic procedure worldwide with a lifetime risk for hysterectomy in the US of 45\% [1]. Uterine fibroids, abnormal uterine bleeding (AUB) and chronic pelvic pain with or without endometriosis are the three major indications for hysterectomy and together, they account for $55 \%-85 \%$ of all hysterectomies [2].

However, in spite of its common practice and advancements in techniques and technologies, hysterectomy is still associated with considerable risks and complications resulting in significant morbidity (15\%-30\%) and mortality (0.03\%-0.04\%) [3]. In 2018, a population-based, retrospective cohort study of 93059 adult women who underwent abdominal hysterectomy from April 1, 2003, to October 1, 2014, in Ontario, Canada, reported a 30-day mortality of $59(0.06 \%)$ [4].

Although the cause of death was not specified in any of the above studies, the most frequent associated morbidities listed were wound complications, venous thromboembolism (VTE), urinary tract infection (UTI), sepsis and blood transfusion. Herein we present a unique case of uneventful abdominal hysterectomy for AUB and uterine fibroins who died from acute dilutional hyponatremia.

Case

\section{Pre-operative care \& informed consent}

A 38-year-old woman, P1G1, BMI $27 \mathrm{~kg} / \mathrm{m} 2$ presented with abnormal uterine bleeding (AUB), severe dysmenorrhea and known uterine fibroids. On examination, the uterus measured up to her umbilicus (20 weeks size). Ultrasound measured the uterus at $15 \times 12 \times 8 \mathrm{~cm}$ with multiple fibroids. Fertility was not desired, and she was using condoms for birth control. She had no significant current medical and no past surgical issues.

Risks and benefits of treatment options including uterine artery embolization (UAE) and total abdominal hysterectomy (TAH) with or without bilateral salpingo-oophorectomy (BSO) were discussed. The patient opted for TAH +/- BSO and risks including injury to ureters, bladder and bowel were discussed.

Pre-operatively, to optimize the patient's hemoglobin and shrink the uterus and fibroids for a possible 'bikini' incision, the patient was prescribed leuprolide acetate $(3.75 \mathrm{mg} \times 3$ months; 
Abbvie, Saint-Laurent, Quebec, Canada) and Estradot patch (Novartis pharmaceuticals, Dorval, Quebec, Canada) for addback therapy to minimize the hypoestrogenic effects of the leuprolide acetate. The patient's immediate preoperative hematology indices are shown in Table 1.

Table 1: Immediate preoperative hematology indices.

\begin{tabular}{|c|c|}
\hline Electrolytes \\
\hline Na-146 & $135-147 \mathrm{mmol} / \mathrm{L}$ \\
\hline K-4.6 & $3.5-5.0 \mathrm{mmol} / \mathrm{L}$ \\
\hline Renal function & \\
\hline Creatinine -72 & $40-90 \mathrm{micmol} / \mathrm{L}$ \\
\hline Urea -5.5 & $3.0-7.0 \mathrm{mmol} / \mathrm{L}$ \\
\hline Hematology & $115-160 \mathrm{~g} / \mathrm{L}$ \\
\hline Hb -105 & $0.35-0.45$ \\
\hline Hct -0.33 & \\
\hline
\end{tabular}

\section{Conduct of surgery}

The surgery (TAH + BSO) was completed uneventfully in 1 hour and 36 minutes, through a Pfannenstiel incision and the estimated blood loss was $100 \mathrm{~mL}$.

The postoperative orders included: IV [intravenous] 2/3:1/3 [solution] - $150 \mathrm{~mL} /$ hour; PCA [Patient Controlled Analgesia]: Morphine x 48 hours. Dose 1-2mg, lockout 5 minutes, 4-hour limit 30mg; Tylenol \# 3, as required.

\section{Post-operative care}

On POD \#1, at 06:00 hours, over a period of 18 hours, the Foley catheter bag contained $450 \mathrm{~mL}$ of urine (approximate rate of 25-30 $\mathrm{mL} /$ hour), and a bolus of $750 \mathrm{~mL}$ of $2 / 3: 1 / 3$ solution was ordered and given.

At 13:00 hours, the visual analogue scale score (VAS) was 0-2 and the Patient Controlled Analgesia (PCA) pump was discontinued after $45 \mathrm{mg}$ of total use of morphine. According to her visiting family, in the late afternoon/early evening, the patient seemed drowsy and at 21:05 hrs, she had a cardiac arrest. Following cardiopulmonary resuscitation (CPR), she was transferred to the intensive care unit (ICU) where she never regained consciousness and at noon of POD \#4, she was declared dead and was taken off all life support systems. The hematology indices in the ICU are listed in Table $2 \& 3$.

Table 2: Immediate postoperative orders.

\begin{tabular}{|c|}
\hline IV [intravenous] 2/3:1/3 [solution] - $150 \mathrm{~mL} /$ hour \\
\hline D/C [discharge] when able \\
\hline Pain Orders \\
\hline PCA [Patient Controlled Analgesia] Morphine x 48 hours. Dose 1-2 mg, \\
lockout 5 minutes, 4-hour limit $30 \mathrm{mg}$ \\
\hline Tylenol \# 3, as required
\end{tabular}

Table 3: Hematology indices throughout the patient's stay in the hospital.

\begin{tabular}{|c|c|c|c|c|c|c|}
\hline Pre-operative & \multicolumn{3}{|c|}{ POD \#1 } & POD \#2 & POD \#4 \\
\hline & $08: 05$ & $21: 10$ & $23: 00$ & $3: 00$ & $5: 35$ & $10: 40$ \\
\hline Na 146 (135-147) & & 118 & 119 & 128 & 135 & 146 \\
\hline K 4.6 (3.5-5.0) & & 2.9 & 2.7 & 3.3 & 4.2 & 3.8 \\
\hline Hb 105 (115-160) & 84 & 92 & 96 & 67 & 90 & 112 \\
\hline
\end{tabular}

According to the Coroner's Report, there were no significant findings and the cause of death was reported as severe brain edema due to hyponatremia. The pathology of the uterus was reported as: specimen weighing 330g; - Endometrium: proliferative endometrium; - Myometrium: leiomyomas; - Ovaries/tubes: no pathologic diagnosis.

\section{Discussion}

This case raises several important issues and questions and provides several learning opportunities including the following.

\section{Potential causes of hyponatremia}

Inappropriate Antidiuretic Hormone (ADH) release: A nephrologist in his Consultation Note stated: "With respect to her hyponatremia, given the acute neurological change, sodium of 119 and cerebral edema, she likely had ADH release postoperatively secondary to pain plus/minus hypovolemia". However, according to the record, at 13:00 hours of POD \#1, the VAS was 0-2 and the PCA was discontinued after $45 \mathrm{mg}$ of total use of morphine. This indicates that the pain had been very well controlled and postoperative pain was never an issue.

Dilutional hyponatremia: The cause of hyponatremia was most likely due to infusion of excessive and/or inappropriate fluid. According to the anesthesia record, the patient had at least $1 \mathrm{~L}$ of Ringers lactate solution pre-/intra-operatively. In addition, the patient received $750 \mathrm{~mL}$ bolus $(2 / 3: 1 / 3)$ in the morning of POD \#1, and possibly $150 \mathrm{~mL} /$ hour x 30 hours $(4500 \mathrm{~mL}$ 2/3:1/3 -hyponatremic solution), in addition to drinking fluids at liberty. Therefore, the patient received approximately $5000 \mathrm{~mL}$ of hyponatremic fluid, $2 / 3$ of which (1.5-2 L) was free water. Therefore, of $5000 \mathrm{~mL}$ of 2/3:1/3 solution, $1 / 3$ (1700 mL) was free water.

Studies from fluid absorption during hysteroscopic/ resectoscopic surgery have indicated that for every $100 \mathrm{~mL}$ of free water absorbed, the serum Na decreases by $1 \mathrm{mmol} / \mathrm{L}$. [5] upon review, it appears that this woman received over $2000 \mathrm{~mL}$ of free water which could potentially account for a decrease in serum $\mathrm{Na}$ in the low 120 s.

\section{Why did this woman die?}

In 1986, Arieff reported on 15 healthy women, aged 22 to 66year, with severe hyponatremia following uncomplicated elective surgery including 5 TAH, 1 D\&C and 11 general surgical procedures. Postoperatively, all patients presented with seizures and coma within 72 hours and 4 died without regaining consciousness while the rest sustained various degrees of significant permanent brain impairment. Although the mechanism of this syndrome, at that time, could not be determined, it was hypothesized that the $\mathrm{Na} / \mathrm{K}-$ ATPase system in the brain is less efficient at extruding $\mathrm{K}$ in women than in Men; likely being inhibited by some female sex hormones such as progesterone and/or its derivatives [6].

In a subsequent review of 4 publications, Ayus et al., found that 36 of 38 patients with postoperative hyponatremic encephalopathy were women. All but one woman either died or 
experienced permanent brain damage, and both men recovered without experiencing neurologic sequelae. In addition, the authors sought to determine potential factors associated with the development of encephalopathy and with its clinical course in patients with postoperative hyponatremia. The authors concluded that women and men are equally likely to develop hyponatremia and hyponatremic encephalopathy after surgery. However, when hyponatremic encephalopathy develops, menstruant women are about 25 times more likely to die or have permanent brain damage compared with either men or postmenopausal women [7].

The available evidence indicates that postmenopausal women and men (TURP syndrome) tolerate/overcome hyponatremia better than women $[7,8]$.

Role of GnRH agonists and estrogen: In 1998, Taskin et al., reported on 17 women undergoing radiofrequency hysteroscopic endometrial ablation randomized to 9 receiving a $\mathrm{GnRH}$ agonist versus 8 receiving saline. The authors found that the Na/K-ATPase pump activity was significantly increased in the GnRH-a group compared with the saline group and correlated with decreased estradiol levels (0.4+/- 0.08 vs $0.26+/-0.06 \mathrm{micromol} / \mathrm{min} / \mathrm{ml}$ [ [9].

\section{Conclusion}

This patient received excessive hyponatremic fluid $(2 / 3: 1 / 3$ solution) infusion which resulted in severe hyponatremia $(\mathrm{Na}<120)$. Although the patient received a GnRH agonist which is known to create a hypoestrogenic state and also reduces the adverse effects of the ATP-ase pump which may be protective against iatrogenic hyponatremia, the addback therapy negated the protective effects of the GnRH-a. The Estradot patch contains $0.585 \mathrm{mg}$ estradiol$17 \beta$ and it delivers $37.5 \mu \mathrm{g}$ daily. This, likely, increased the serum estradiol level sufficiently to estrogenize the endometrium since the pathology report indicated a proliferative endometrium.

\section{Acknowledgement}

None.

\section{Conflict of Interest}

No conflict of interest.

\section{References}

1. Merrill RM (2008) Hysterectomy surveillance in the United States-1997 through 2005. Med Sci Monit 14(1): CR24-CR31.

2. Jacobson GJ, Shaber RE, Armstrong MA, Hung YY (2006) Hysterectomy rates for benign indications. Obstet Gynecol 107(6):1278-1283.

3. Wiser A, Holcroft CA, Tulandi T, Abenhaim HA (2013) Abdominal versus laparoscopic hysterectomies for benign diseases: evaluation of morbidity and mortality among 465,798 cases. Gynecol Surg 10(2): 117 122.

4. Kelly EC, Winick-Ng J, McClure JA, Peart T, Chou Q, et al. (2019) Hysterectomy in Ontario: A Population-Based Study of Outcomes and Complications in Minimally Invasive Compared With Abdominal Approaches. J Obstet Gynaecol Can: S1701-S2163.

5. Istre O, Skajaa K, Schjoencby A, Forman A (1992) Changes in serum electrolytes after transcervical resection of endometrium and submmucous fibroids with glycine $1.5 \%$ for uterine irrigation. Obstet Gynecol 80(2): 218-222.

6. Arieff AI (1986) Hyponatremia, convulsions, respiratory arrest, and permanent brain damage after elective surgery in healthy women. $\mathrm{N}$ Engl J Med 314(24): 1529-1535.

7. Ayus JC, Wheeler JM, Arieff AI (1992) Postoperative hyponatremic encephalopathy in menstruant women. Ann Intern Med 117(11): 891897.

8. Fraser CL, Kucharczyk J, Arieff AI, Rollin C, Sarnacki P, et al. (1989) Sex differences result in increased morbidity from hyponatremia in female rats. Am J Physiol 256(4 Pt 2): R880-R885.

9. Taskin O, Buhur A, Birincioglu M (1998) Endometrial $\mathrm{Na}^{+}, \mathrm{K}^{+}$-ATPase pump function and vasopressin levels during hysteroscopic surgery in patients pretreated with GnRH agonists. J Am Assoc Gynecol Laparosc 5: $119-124$ 